\title{
THE EXCEPTIONS TO COLLES' LAW
}

\author{
BY \\ GEORGE OGILVIE, B.Sc., M.B.Edin., M.R.C.P.Lond., \\ PHYSICIAN TO THE HOSPITAL FOR GPILEPST AND PARALYSIS, \\ REGRNT'S PARK
}

Received November 5th, 1895-Read January 28th, 1896

THE statement made by Colles in 1837, that he had never seen or heard of a case in which a healthy mother had contracted syphilis by suckling her congenitally syphilitic child, has been raised to the rank of a law which goes by his name. It enjoys up to the present day universal recognition in the teaching of this country. Our authorities agree that it holds good without exception. Berkeley Hill in 1881 said $^{1}$ that "This statement of Colles made forty-four years ago, has never been controverted. Of the few cases called exceptions, not a single one bears investigation." In $1893 \mathrm{Mr}$. Hutchinson said ${ }^{2}$ that "since Colles' day no exceptions to his law have I think been put on record which are worthy of trust." And in the last edition of Cooper's book (1895) we read ${ }^{3}$ that "a careful examination of these cases-brought forward as exceptions-will demonstrate that owing to want of very vital points in the recorded histories, the

\footnotetext{
1 'Syphilis and Local Contagious Disorders,' 2nd ed., 1881, p. 53.

2 'Syphilis,' 1893, p. 91.

3 'Syphilis,' 2nd ed., 1895, p. 352.
} 
evidence rather tends to support Colles' law than to refute it." The same view has been expressed by Hilton Fagge, ${ }^{1}$ Lane, ${ }^{2}$ Van Harlingen, ${ }^{3}$ Bumstead, and Taylor, \&c.

A complete collection with analyses of the cases published as exceptions since 1854 does not exist. So far as I have been able to ascertain, their number is twenty. They differ in completeness, but some amongst them seem to me as conclusive as any recorded clinical facts can be. Of these I desire to submit to you two. My reason for selecting these two cases and giving them in full, is that Ranke's case has never yet been presented in the complete and convincing form in which it exists, his later report of the case having been entirely overlooked; and that Merz's case, although published in 1889 and closely approaching the exactness of a pathological experiment, has been altogether ignored. Other cases like those of Pellizzari, Zeissl, and others, are practically on identical lines with the two quoted, and their narration now would only be repetition. Behrend in $1881^{5}$ undertook the task which I am now attempting of disproving the universal validity of Colles' law. He failed because he relied on Ranke's case in its incomplete form, and on the case of Guibout, which does not bear examination. He also erred in his historical data, as was first shown by Diday.

\section{Ranke's Case ${ }^{6}$}

The father, 30 years old, infected about eleven years ago, has been without symptoms for nine years. Married three years

1 'The Principles and Practice of Medicine,' vol. i, 2nd ed., 1888, p. 330.

2 'Lectures on Syphilis,' 1881, 2nd ed., p. 59.

3 “Venereal Diseases and Syphilis." 'The International Encyclopædia of Surgery,' ed. by John Ashurst, vol. ii, Lond., 1882, p. 558.

4 'The Pathology and Treatment of Venereal Diseases,' 5th ed., 1883, p. 807.

5 ' Berlin. Klin. Wochenschrift,' pp. 126 and 127, 1881.

- Ranke (Gröningen) "Ueber Ansteckung der Mutter mit Lnes hereditaria durch ihr eigenes Kind," "Tageblatt der 51 Versammlung deutscher Naturforscher und Aerzte in Cassel,' 1878, No. 4, p. 94. 
ago, he begot in the first year of his married life a syphilitic child, which recovered after repeated calomel treatment.

The mother remained healthy until after the second confinement. The second child, born at the end of the third year, developed in the second week a macular exanthematous rash and marked ulcers at the angles of the mouth. Whilst suckling this child a small excoriation on the left nipple developed into a typical hard chancre, followed by a roseolar eruption of great severity. Inunction treatment effected a cure for the time; a relapse was treated in the same way.

During the time of observation, from the seventh month of the second pregnancy, no symptoms of disease were observed, either in the husband or in the eldest child. No milk had been drawn off by a third person.

It is, therefore, certain that the healthy mother of a syphilitic child was infected with syphilis, and with a probability approaching certainty, by her own child, while suckling it.

The case will be given more in detail at another place.

This promise was not fulfilled until 1883, when the following additional communication was made. ${ }^{1}$

The diagnosis of hereditary syphilis in the first born child rests exclusively on indirect evidence (report of the father, and the production of the prescriptions given for the child by the doctor formerly in attendance). This child is said to have had, besides other obvious manifestations of syphilis, ulcers at the angles of the mouth. It was not, however, suckled by the mother, having been brought up by bottle.

Before the birth of the second child a few small, slightly sensitive glands could be felt in both axillæ of the mother, which seemed to be connected with a slight intertrigo below the pendulous mammæ. A very careful examination, made during pregnancy, gave absolutely no support to the diagnosis of syphilis. After the appearance of the hard chancre on the nipple, the glands in the left axilla enlarged into a considerable mass. By this time painful swellings of the joints appeared with rather high fever, which at first made one think of an onset of acute articular rheumatism. With regard to the successive development. of symptoms, the further course, however, was throughout typical,

1 Paul Michelson, “Zum Kapitel der hereditären Syphilis" (Einiges Nähere über den Fall Ranke's), Unna's 'Monatshefte für praktische Dermatologie,' Band ii, p. 366, 1883. 
and showed that one had only to deal with the prodromal symptoms of the eruption of a papular syphilide, appearing first on the surface of the chest and belly and spreading nearly over the whole body.

In the discussion which followed Ranke's communication, the late Dr. Busch, Professor of Surgery in the University of Bonn, reported a case of the same kind.

\section{Merz's Case ${ }^{1}$}

M. B-, 34 years old,contracted syphilis at the age of twenty-nine The disease developed in the ordinary way, and three years after its appearance M. B-believed that he might marry without danger as he had not suffered from any specific accidents for six months. Two months after his marriage he had on the tongue and in the mouth a fresh outbreak of mucous patches. Being very attentive to the appearance of the least symptom, very careful with regard to himself, besides being very anxious to have healthy children, he at once submitted himself to the "mixed treatment," and at the same time he took all the necessary precautions to avoid the communication of the disease to those surrounding him. Since that period he has never had any relapse; he has, nevertheless, continued the treatment at regular intervals. In December, 1887, six or eight months after the attack in question, his wife became pregnant. The pregnancy progressed in the normal way, and on the 1st October Madame B-was delivered, at the full term, of an apparently healthy and well-nourished boy. I must add that at the request of $M$. B-I had on several occasions examined his wife-who thoroughly grasped the situation-and that I had never seen anything which could lead one to suspect infection. I also examined the child at the time of its birth, and naturally ordered suckling by the mother.

All went well during a fortnight, till the parents, who at $m y$ advice examined carefully every day their child at every aperture, discovered one morning a slight excoriation on the upper lip.

Being called the same day, I found a superficial abrasion, opalescent, of the diameter of a large bean, and much resembling a mucous patch. I warned the parents that this might perhaps be the first manifestation of specific disease, but as I counted

Merz, M., "Exception à là loi de Baumès dite loi de Colles," 'Bulletin médical de l'Algérie,' 1re Année, No. 1, pp. 16-26, 1889. 
upon the maternal immunity, I reassured the mother as to the risks of a possible infection, and I strongly urged ner to continue suckling as if nothing existed. I little suspected that I was going to have the sad privilege of witnessing an infringement oi the law. During the following days other patches appeared on the lips, the tongue, and the internal surface of the cheeks of the child, together with a circumscribed eruption of pemphigus on the legs and hands. On the appearance of the first symptoms the mother had been subjected to treatment, and everything disappeared at the end of ten days. About a month afterwards, upon meeting the father, he informed me that for a week his wife had suffered from very painful fissures in the left nipple. I prescribed frequent applications of a solution of cocaine, the pain diminished, but the fissures persisted. I visited the mother eight days afterwards, and found all around the nipple ordinary cracks, but on the left gide a rounded cup-shaped erosion of little depth, about the size of a five-franc gold piece, ham-coloured and iridescent on the surface, slightly painful, bleeding rather easily, but not discharging pus. On palpating the ulcerated part between the thumb and forefinger, I thought I could detect a vague induration. In the axilla there were some small hard glands moveable under the skin. As the patient was undergoing the "mixed treatment," I had nothing else to do but to suspend my diagnosis and watch her. The further development was typical. The ulceration developed exactly like a chancre. It healed in a fortnight and was followed after thirty days by a splendid roseola, accompanied by loss of the hair and by a mucous patch on the inner surface of the right cheek. I may add now that no other accident followed, thanks to a vigorous treatment. Fortunately the milk did not dry up, and the child continued to be suckled. Both are or seemed to be actually cured.

In this case the medical adviser, convinced of the practical teaching of Colles' law, acted upon it with the unfortunate result of producing just what the law pretends to guarantee against.

Cases like these must be rare even if the fact which they establish were of more frequent occurrehce than it seems to be. To give them the conclusiveness which they possess, several conditions have to be fulfilled, which for 
obvious reasons cannot often all be substantiated in an individual case. These conditions are the following :

1. The previous disease of the father has to be established.

2. It has to be proved by medical evidence that the disease of the child is syphilis. All cases have to be dismissed in which the previous history of the child as regards symptoms rests upon the evidence of relations, \&c., because some non-syphilitic diseases of infancy closely resemble congenital syphilis.

3. It must be established that the disease of the child is congenital and not acquired. In this respect we have only one but an all-important point for guidance-the time of the appearance of the disease in the child, as the primary sclerosis might be missing or overlooked, and as in every other respect the acquired disease might closely mimic the congenital form. But even suppose that the child is infected at the day of its birth, taking for the first and second incubation the shortest possible intervals of two weeks and three weeks respectively, it could not present a syphilitic skin eruption, and an affection of the mucous membrane of the mouth due to acquired syphilis before the sixth week. Therefore only those cases can be accepted as conclusive in which the general syphilitic disease of the child appeared within the first five weeks. Practically, however, the outbreak of secondary symptoms up to two months or more after birth can be attributed to the hereditary form of the disease.

4. It must also be certain that the ulcer appearing at the mother's breast is a primary sore, and here again we have only one criterion to rely upon, viz. that the indurated ulcer is followed in due time not only by glandular swellings in the axilla, but by a rash, throat affection,-in fact, by the ordinary sequelæ of the disease. It is well known that in people with latent syphilis irritation of the skin may produce ulcerating sores. These sores may become indurated, as is the case, for instance, in the relapsing chancre, which, although occasionally 
appearing without any appreciable cause, might follow irritation or herpes of the prepuce. Therefore the fact that the ulcer on the mother's breast is indurated, does not in itself prove its primary character any more than the want of induration would disprove it. Swolleu glands in the axillæ might follow any ulcerative process of the mammæ whether syphilitic or not, and if syphilitic whether primary or not. The incisive difference between the irritation ulcer and the primary sore is that the former is not followed by secondary symptoms.

5 . We have further to ascertain that the mother has not suckled any other child than her own, nor been exposed to contracting the disease from any other source. About these two points, in private practice particularly, information can be obtained which is not subject to any reasonable doubt.

That these conditions should all be fulfilled in the same case must evidently be rare. If it happens, an exception to Colles' law is established.

But from another point of view also the comparative scarcity of conclusive cases is easily explained. I do not think that any one now-a-days doubts that a child affected with congenital syphilis may communicate the disease to a healthy wet-nurse by suckling, but about the frequency of this occurrence the greatest diversity of opinion exists. It appears that Colles considered accidents of this kind by no means rare. Continental syphilographers have described epidemics of the disease spread in this way. On the other hand, a man of such large experience as Henoch ${ }^{1}$ confesses to never having met with a case. Only quite recently Mr. Parker $^{2}$ reported his own experience to a like effect from the Shadwell Hospital for Children. According to Mr. Hutchinson ${ }^{3}$ syphilitic infants when put to wet-nurse so

1 New Sydenham Society, vol. cxxv, 'Lectures on Children's Diseases,' vol. i, p. 119.

2 ' Brit. Med. Journ.,' February 9th, 1895.

3 'Syphilis,' 1893, pp. 94, 95. 
rarely communicate the disease that some surgeons to lying-in hospitals with very large opportunities for observation have expressed disbelief as to its possibility.

This discrepancy cannot be satisfactorily explained by the fact alone that in different countries, and in the same country at different times, the proportion between children brought up by hand and those brought up at the breast shows great variations. It is partly accounted for by the circumstance that the syphilographer's experience must necessarily be at variance with that obtained in lying-in hospitals, children's and foundling hospitals. A ccllective investigation, embracing the institutions just named, could alone settle this open question, which the experience of no single man, however vast it be, can satisfactorily answer.

If infection of a nurse by suckling is rare, and if the above conditions have to be fulfilled to establish conclusive cases of infection of a mother by her own child, their comparatively small number is fully accounted for. Their number would probably be larger if the opportunity of closely watching mother and child for several months, in hospital practice at least, would offer itself more frequently; and it would be still larger if some cases had not been excluded and been put down to acquired syphilis in the child, only for the reason that those who had the chance of observing them were imbued with the teaching of Colles.

If Colles' law were valid it would have an important practical as well as theoretical bearing. If it is only the expression of the personal experience of some at variance with that of others, the practical as well as the theoretical conclusions fall to the ground.

Practically Colles' law teaches that the healthy mother can suckle her own congenitally syphilitic child with impunity. The so-called exceptions teach that she cannot do so, and that therefore she, no more than a hired nurse, should be allowed to expose herself to the risk 
which she might run. In some particular case it may be justifiable to put a congenitally syphilitic child to the breast of a healthy wet-nurse who has been informed of the danger she runs. So it may be justifiable occasionally not to prevent a healthy mother from suckling her syphilitic infant. In cases of this kind, a conflict of various interests exists which cannot be settled on purely medical lines. Moral, legal, and sentimental considerations determine the decision to be arrived at. From a medical point of view no justification exists.

The theoretical consequence of Colles' law would be that a mother who has given birth to a syphilitic child is immune against infection by it, although she has no symptoms of the disease and never had any. This immunity has been regarded as proving the existence of latent syphilis in the mother. With what we know now on the relation between disease and immunity such an argument is not admissible. In fact, the present phase of bacteriological knowledge seems to readily offer a theoretical explanation drawn from analogy. If the normal placenta represents a filter between the circulation of the mother and that of her child for all formed substances, the passage of microbes from one circulation to the other through the placenta (at one time regarded as impossible, but now definitely proved) presupposes damage to the cell layers. On the other hand the noxious effect of the toxines produced by the organisms and carried by the blood might pass from one circulation into the other by chemical interchange. Applying this to the question of transmission one might argue that infection only takes place through the microbes and the lesions they cause, while the immunity is established by the toxines and their diffusion through the blood. Simple and plausible as such an explanation might sound it is mere speculation, and at the same time insufficient, because, apart from other things, it leaves unexplained those cases in which neither infection nor immunisation takes place. Such cases occur not only in syphilis, but 
also in other transmissible diseases. The child born healthy of a mother affected with smallpox can contract the disease during parturition or in early extra-uterine life, and must therefore be protected by vaccination. Vaccination of pregnant women with vaccine lymph produces immunity in the child against vaccination in at most only one third of the cases.

A certain liking for symmetry and the rounding of theories has evidently given rise to the extraordinary pendant to Colles' law which is known abroad as Profeta's ${ }^{2}$ law, and which says that a child born healthy of a syphilitic mother is immune against its mother's disease, and can therefore be suckled by her with impunity. Going a step further it has been contended that a healthy child is immune against infection by the secondaries of its father, if the latter was syphilitic at the time of generation. That exceptions to Profeta's " law" exist was admitted

1 Transmission of smallpox from mother to fœtus is of an erratic character. The child may be born dead with or without smallpox. The child may be born alive with smallpox. The child may be born apparently healthy, and develop smallpox shortly after birth (say two days); in this case also the disease was contracted in utero. The child may be born healthy, and either remain healthy or contract smallpox in extra-uterine life; in the latter case it nearly invariably dies; to protect it it has to be vaccinated, which can be done successfully. The child may, during an epidemic, contract smallpox in utero, the mother, who was vaccinated previous to gestation, escaping. Of twins one only may be born with smallpox.

It seems that while intra-uterine transmission of smallpox is by no means rare, intra-uteriue immunisation seldom if ever takes place. The two antagonistic statements to be met with, that if a pregnant woman auffers from smallpox her fœtus will also be affected, and that the child is always born free from the disease, are both wrong. They are merely expressions of personal experience and knowledge. Smallpox occurring during pregnancy is in a large percentage of cases instrumental in producing abortions and still-births. In the majority of such cases the fœtus shows no signs of actual or past disease. Still, eruption or scars indicating intranterine infection may be found on the dead fotus, as well as on the living child, at the time of delivery. The child, if born free from the disease, and remaining healthy, is neither refractory to smallpox nor to vaccination.

'Trattato Pratico delle Mallattie Veneree,' Palermo, 1888, pp. 980, 981. 
by him, and also by Diday when the latter gave the law its name. Since that time other observers have brought forward exceptions. In fact, I am not sure that they are lessin number than those examples which might be adduced to support this so-called law. Anyhow, we know that a healthy child born of a syphilitic mother can contract syphilis from her in its extra-uterine life, and it naturally follows that the child has to be protected against this possible source of infection. That in face of these granted facts one could act and teach others to act upon the rule, affords a remarkable instance of conviction obscuring judgment.

It is still possible that within certain limits Colles' law and its pendant express a clinical fact, viz. that under unknown conditions during gestation a reciprocity is established between fœtus and mother with regard to conveying immunity. The frequency with which this takes place has still to be found. But whatever the proportion may turn out to be between those cases which at present are considered exceptional, and those cases which would exemplify the rule, our practical dealing is determined by the former.' 'The practical consequences of

1 The case is similar to that of vaccination syphilis. Vaccination syphilis, although fully established, is rare. Amongst the cuses published as such there are undoubtedly many in which products of hereditary syphilis, eruptions following ordinary vaccination, non-syphilitic induration changes in the vaccine pustules have been mistaken for vaccination syphilis. On the other hand there is no doubt that for obvious reasons it has been thought desirable to suppress occurrences of this kind. If these two considerations to a certain extent balance each other, the fact still remains that vaccination syphilis is rare. Only in this way can it be explained that men with unusually large opportunities for observation confess to never having seen a case of this kind. No other explanation can be given for such a fact as that reported from the Vienna Foundling Hospital, where, amongst more than 100,000 cases of vaccination, extending over thirty-five years, not a single case of vaccination syphilis occurred, although little or no care was taken to prevent such accidents. Only in the same way can be explained the long array of negative evidence which clinical as well as experimental experience has furnished with regard to the vaccination of healthy from syphilitic subjects. Nevertheless, all those who grant the existence of vaccination 
the law break down since the exceptions are established. To ignore the exceptions or disprove them, and act upon the rule, is one thing. To accept the exceptions, and put aside the rule, is another thing. But how anyone can accept the exceptions, and act upon the rule, like Fournier ${ }^{1}$ and others, I fail to see.

In accordance with the actual wording of Colles' law I have restricted myself to the consideration of cases where the source of the mother's infection was her own child. No facts exist to show that a mother immune against her child's disease can still contract the disease from other sources. Granted that immunity against the child's or the mother's disease respectively means immunity altogether, then the rules referred to can in a more concise form be thus expressed:

1. A healthy mother who has given birth to a congenitally syphilitic child is immune against syphilis.

2. A healthy child born of a mother suffering from acquired syphilis is immune against syphilis.

With regard to this wider conception of what is understood as Colles' law, its fallacy is still more completely shown by those cases in which the mother of a congenitally syphilitic child contracts fresh syphilis shortly before or after delivery. Against this positive evidence the few negative inoculation results have no weight.

All the exceptions to Colles' law in its wider sense are conclusive examples of a purely paternal infection of the fœtus presenting the following features: acquired syphilis in the father, congenital syphilis in the child, acquisition of syphilis by the mother shortly after delivery.

syphilis agree that by these exceptional occurrences our practical dealing with regard to vaccination has to be guided.

1 Fournier's position in this question is all the more surprising, as it is in open contradiction to what he argues and advocates in vaccination syphilis. With regard to the latter he emphasises that " all the negative facts in the world could not outweigh one positive authentic fact," and from the positive facts he draws the practical conclusions. With regard to Colles' law he accepts the positive facts observed by others, but he fails to draw the unavoidable conclusions. 
In conclusion, and in connection with the subject of this paper, I beg to lay before this Society the following suggestions, which might, perhaps, advantageously form the basis of a collective investigation.

1. Collect cases in which a congenitally syphilitic child has infected its own mother by suckling.

2. Collect cases in which a healthy mother who has given birth to a congenitally syphilitic child, has been infected with fresh syphilis from some other source shortly before or after delivery.

3. Collect cases in which a healthy born child has contracted syphilis from its mother, those cases being excluded where the mother's syphilis was acquired after the birth of the child or too late in gestation to be transmitted.

4. Collect cases in which a child born healthy of a syphilitic mother contracts syphilis from some other source.

By the publication of Dr. Coutt's ${ }^{1}$ case, although it is, as I have stated elsewhere, ${ }^{2}$ not quite conclusive, the first impulse was given in this country to critically approach the traditional teaching on this question. It has furthermore already elicited from $\mathrm{Mr}$. Parker ${ }^{3}$ the information that his own experience furnishes him with at least one exception to Colles' law. A more extended inquiry is sure to produce further results.

1 ' Lancet,' June 9th, 1894.

2 'Lancet,' June 23rd and July 28th, 1894.

3 'Brit. Med. Journ.,' February 9th, 1895.

(For report of the discussion on this puper, see ' Proceedings of the Royal Medical and Chirurgical Society,' Third Series, vol. viii, p. 106, also at p. 155.) 